\title{
A suspensão do cotidiano: a imigração nas imagens do filme Bem- vindo
}

\section{The suspension of everyday life: immigration in the images from the movie Welcome}

\author{
Eliane de Oliveira ${ }^{1}$
}

\begin{abstract}
Resumo
Neste trabalho, analisamos a interrelação entre cotidiano, cinema e imigração. Para isso, partimos de situações apresentadas no filme Bem-vindo, produção francesa de 2009, dirigida por Philippe Lioret, que narra a história de um jovem iraquiano que está na França, tentando chegar à Inglaterra. Entremeadas com diversas narrativas pessoais, estão a situação imigratória na França, a legislação, a rotina dos sujeitos envolvidos: policiais, moradores, imigrantes. Utilizamos como referencial teórico o conceito de cotidiano de Agnes Heller, assim como estudos de Edgar Morin sobre cinema e de imigração de Zigmunt Bauman. Diante de uma superexposição imagética cotidiana, entendemos que o cinema se constitua um espaço privilegiado para essas discussões, por sua lógica de recepção. Da mesma forma, observamos que o filme escolhido apresenta questões atuais e oportunas, ao mesmo tempo particulares e genéricas, tais como a suspensão do cotidiano, o retorno a ele modificado e a superação de estereótipos, prejulgamentos e generalizações relacionadas à imigração que, embora comuns e, em certa medida, necessárias à vida cotidiana, impõem limitações à cidadania.
\end{abstract}

Palavras-chave: Comunicação. Cinema. Imigração. Cotidiano

\begin{abstract}
In this paper we analyze the interrelationship between everyday, cinema and immigration. For this, we start from the situations presented in the film welcome, French production of 2009, directed by Philippe Lioret, wich tells the story of a young iraqi who is in France, trying to get to England. Interspersed with several personal narratives, are the immigration situation in France, legislation, the routine of the subjects involved: police, residents, immigrants. We use the theoretical concept of everyday Agnes Heller, as well as studies on film and Edgar Morin immigration Zigmunt Bauman. Before an overexposure imagery everyday, we understand that the film would constitute a privileged space for these discussions by your logic reception. Similary, we observed that the film presents selected current issues and timely, while private and generic, such as suspending the daily, return to it and modified overcoming stereotypes, prejudices and generalizations related to immigration, although common and to some extend, necessary for everyday life, impose restrictions on citizenship.
\end{abstract}

Keywords: Communication. Film. Immigration. Everyday

\section{Introdução}

Entre as distintas repercussões geradas pelos atentados de 11 de setembro de 2001, pode-se afirmar que a questão imigratória ganhou mais visibilidade. Se historiadores ainda não chegaram a um consenso sobre o uso ou não da data como marco inaugural de uma nova época, é certo que, em muitos aspectos, há, sim, um antes e um depois. A imigração é um deles. É inegável que houve uma expansão do policiamento, de legislações

${ }^{1}$ Universidade Estadual de Londrina. Email: eliello@hotmail.com. 
referentes ao tema, de deportações, enfim, a questão imigratória adquiriu espaço em uma série de discussões políticas, econômicas e sociais. Em muitos desses casos, porém, o imigrante, o indivíduo envolvido no processo imigratório foi deixado de lado ou não foi considerado sujeito, o mesmo ocorrendo com o cidadão local que, muitas vezes, é lembrado somente como justificativa para as medidas repressivas adotadas.

Neste trabalho, buscamos analisar a imigração pelo que ela pode ter em comum, genérico, independente do local geográfico adotado - o caráter cotidiano. Neste sentido, utilizamos, como objeto de estudo, o filme Bem-vindo (WELCOME, 2009) direção de Philippe Lioret, França, com o qual, temos trabalhado em diferentes estudos, e o conceito de cotidiano de Agnes Heller. Entendemos que uma película seja apropriada para este objetivo, pois, como afirma Heller (2004), o reflexo artístico e o reflexo científico rompem com a tendência espontânea do pensamento cotidiano, tendência orientada ao $\mathrm{Eu}$ individualparticular. A arte realiza tal processo porque, graças à sua essência, é autoconsciência e memória da humanidade. Especificamente em relação ao filme escolhido, acreditamos que ele cumpre, "enquanto autoconsciência e memória que é da história humana, a função de 'elevar' a particularidade individual ao genericamente humano” (HELLER, 2004).

\section{A Imigração nas Imagens em Movimento}

Bem-vindo narra a história de Bilal, um jovem iraquiano de origem curda que está em Calais, na França, tentando chegar à Inglaterra para encontrar sua namorada, que está prestes a se casar com outra pessoa, um casamento arranjado pela família. Desde a saída do Iraque, foram três meses viajando escondido em trens e caminhões; porém, a travessia do Canal da Mancha será mais difícil. Além da intensa fiscalização policial, que tenta impedir imigrantes de atravessar para a Inglaterra escondidos em caminhões, ele tem que superar os traumas causados por agressões cometidas pelo exército turco. Após uma tentativa frustrada, na qual todos os clandestinos são descobertos porque Bilal não consegue respirar com a cabeça dentro de um saco, o jovem resolve fazer a travessia nadando. É neste ponto que sua história se cruza com a de Simon, um solitário professor de natação, frustrado com o processo de divórcio. Sensibilizado com a luta do jovem para fazer a travessia, Simon decide treinálo, no início, aparentemente, é para impressionar a ex-mulher, Marion, uma professora que participa de ações para auxiliar os imigrantes, entre as quais, a distribuição de sopa no cais do porto.

Já nas primeiras aulas, Bilal demonstra não apenas habilidade, mas um grande empenho. Tanta dedicação desperta curiosidade em Simon, que se surpreende ao saber que todo esforço é para o adolescente reencontrar a namorada.

Em uma noite, Simon encontra Marion, casualmente, em um supermercado. $\mathrm{Na}$ saída, dois jovens imigrantes são impedidos de entrar. A alegação do segurança é que eles perturbam os clientes. Indignada com a situação, Marion interpela alguns clientes, mas é contida pelo gerente do estabelecimento e se irrita ainda mais com a passividade de Simon.

No caminho para casa, ele encontra os garotos e os leva para seu apartamento. Entre pizza e cerveja, eles conversam e Simon vai se familiarizando com as histórias de Bilal que, além de reencontrar Mina, sonha em ser jogador de futebol no Manchester United. No meio da noite, Simon encontra Bilal no banheiro com um saco na cabeça. Irritado e surpreso, não entende a situação, porém, o jovem explica que a polícia utiliza detectores de gás carbônico para descobrir clandestinos escondidos nos caminhões. É preciso conseguir respirar com a cabeça dentro do saco, para não ser descoberto.

Na sequência, Simon tem que ir à delegacia dar explicações à polícia. Sua carona aos jovens curdos não passou despercebida. Por lei, os habitantes 
de Calais são proibidos de auxiliar imigrantes. Assustada com a situação, Marion tenta alertá-lo que um voluntário foi preso por abrigar refugiados. Simon parece não se importar com o que possa lhe acontecer. Após a audiência de separação, confessa à ex-mulher que pretende treinar Bilal de maneira mais intensa, e demonstra admiração pela coragem do jovem e por seus motivos.

Porém, ajudar imigrantes não é uma tarefa fácil. A vigilância é constante e parece estar em todo lugar. O cais do Porto, local utilizado pelos voluntários para a distribuição de sopa aos refugiados, é conhecido da polícia que, em uma 'visita', prende algumas pessoas. Assustados, os que não foram presos se refugiam em uma floresta próxima. É lá que Simon reencontra Bilal e, outra vez, o leva para sua casa. Preocupado, Simon questiona por que ele não fica na França e aproveita a possibilidade de se tornar um nadador, um bom nadador como o próprio Simon fora na juventude. Ele chegou a ser campeão francês. É a falta dessa medalha que origina uma discussão. Simon acusa Bilal. No desentendimento, eles saem do apartamento, um vizinho se incomoda e discute com Simon.

Em virtude dessa confusão, a polícia vai ao apartamento para fazer uma revista, sob a acusação de que ele abriga clandestinos. Sem encontrar nada, os policiais vão embora, porém, fazem uma advertência - irão voltar. Antes de fechar a porta, após a saída dos policiais, ele olha para o apartamento do vizinho que, provavelmente, fez a denúncia. Ironicamente, os dizeres do tapete da porta do vizinho dão nome ao filme.

Ao entrar no banheiro e perceber a ausência da roupa de natação, Simon vai à praia. Sem encontrar Bilal, pede ajuda à guarda-costeira. $\mathrm{Na}$ identificação do desaparecido, dá seu sobrenome a ele, na esperança de que isso ajude. Contudo, em uma conversa com Marion, é alertado de que as buscas por um imigrante ilegal não receberão muito empenho.

Já na delegacia, é informado de que, após cinco horas, Bilal foi encontrado por um pescador, que teve de retirá-lo do mar à força. É informado, também, que está sob custódia judicial, que será acusado de ajudar pessoas em situação ilegal, e está impedido de deixar a região. Ao ir novamente ao porto, encontra Bilal na fila da sopa, porém, é aconselhado pelos voluntários a deixar o local, para não prejudicá-los. Em outro chamado à delegacia, Simon recebe sua medalha e a notícia de que Bilal foi encontrado pela marinha a 800 metros da costa inglesa.

\section{A Vida de Todos os Dias}

"Todo dia ela faz tudo sempre igual...", é assim que começa a música Cotidiano, de Chico Buarque. Neste mesmo sentido, Netto e Carvalho (2011) definem a vida cotidiana como a contiguidade dos mesmos gestos, ritos e ritmos de todos os dias. Essas atividades rotineiras são executadas mais pelo gesto mecânico e automatizado do que pela consciência.

Ou seja, é no cotidiano que o homem se constitui. Nesta vida de todos os dias, ele entra em contato com outras pessoas, grupos, instituições, acontecimentos que irão compor sua identidade. É no cotidiano que ele se realiza. O cotidiano tem assim, em princípio, um caráter individual, particular, como se pudesse ser resumido à esfera privada; porém, Lefebvre (1981 apud NETTO; CARVALHO, 2011) aponta que o Estado Moderno gere o cotidiano direta ou indiretamente. Diretamente pelos regulamentos e leis, pelas proibições ou intervenções múltiplas, pela fiscalização, pelos aparelhos da Justiça, pela orientação da mídia, pelo controle das informações:

Para a produção capitalista de bens de consumo, também o cotidiano é um centro de atenção, uma base de rentabilidade econômica inesgotável [...] Através dos meios de comunicação tais máquinas e utensílios se apresentam como sedução permanente ao prático, ao pragmático, ao mágico, ao ilusório [...]. Vista sob um certo ângulo, a vida cotidiana é em si o espaço modelado (pelo Estado e pela produção capitalista) para erigir o homem em robô: um robô capaz de consumismo dócil e voraz, de eficiência produtiva e que abdicou de sua condição de sujeito, cidadão (NETTO; CARVALHO, 2011, p. 18, 19). 
Neste sentido, a vida cotidiana constitui-se um espaço não só do conjunto de atividades que caracterizam a reprodução dos homens singulares, mas, também, um espaço de possibilidade da reprodução social. É nela que o homem aprende as relações sociais e as reproduz para e enquanto instrumento de sobrevivência. Como o homem é consciência, sua produção não se restringe somente à sobrevivência ou à singularidade. Nesta vida cotidiana, este homem encontra-se em potência, ainda que nem sempre realizável.

Para Netto e Carvalho(2011), as determinações da cotidianidade fazem com que todo e cada indivíduo só se perceba como ser singular, a dimensão genérica (a referência à pertinência ao humanogenérico) aparece subsumida, na vida cotidiana, à dimensão da singularidade. A superação desta singularidade ocorre, de acordo com Heller (2004), na passagem do homem inteiro para o inteiramente homem. Tal passagem ocorre no rompimento da cotidianidade, quando um projeto, uma obra ou um ideal convocam a inteireza de nossas forças e, então, suprime a heterogeneidade. Há nesse momento uma objetivação. A homogeneização é a mediação necessária para suspender a cotidianidade. É esta suspensão do cotidiano que permite um retorno de forma modificada. Acreditamos que, em Bemvindo, o encontro entre os personagens de Simon e Bilal promove esta suspensão do cotidiano, não simplesmente como uma 'alteração na rotina', mas possibilitando realmente uma mudança substancial.

\section{O Cinema, a Imigração e a Suspensão do Cotidiano}

O cinema surge apresentando ao público o comum e o rotineiro. Para Morin (1970), é nisto que reside a genialidade da invenção: filmar e projetar como espetáculo o que não é espetáculo, fazer as pessoas se maravilharem com tudo em outra circunstância não causaria tal sensação. Dar ao cotidiano um caráter especial, único, mágico. Para
Morin (1970), o cinema reflete a realidade, e, mais do que isso, comunica com o sonho. É esta magia do cinema que, ao comunicar sonho e realidade, possibilita avanços e retrocessos no tempo, viagens ao passado e ao futuro e, em alguns casos, antecipa a realidade. É esse limiar entre realidade e ficção, tão característico do cinema, que possibilita uma função social que, muitas vezes, supera a do puro entretenimento.

Como síntese das mais diversas manifestações estéticas do homem, como literatura, pintura, música, arquitetura, fotografia, entre outras, as utiliza para apresentar ficção e realidade, por meio de situações humanas típicas. É um medium entre realidade e imaginário, o que significa não apenas comparar e apreender o que já é conhecido, mas, também, um encontro com o desconhecido, seja diretamente ou por meio de sugestões. O cinema é dialético; o filme tem sua duração específica, mas ele é capaz de conduzir a reflexões que vão além da sala de cinema ou do tempo de duração da película. Etienne Souriau (apud AUMONT, 1995) afirma que os fatos espectatoriais prolongam-se bem além da duração da projeção: integram principalmente a impressão do espectador, quando sai do filme e todos os fatos que se referem à influência profunda exercida em seguida pelo filme, seja pela lembrança, seja por uma espécie de impregnação produtora de modelos de comportamento.

Para Metz (1972), o segredo do cinema consiste em conseguir colocar muitos índices de realidade nas imagens que, enriquecidas deste modo, passam a ser percebidas como reais. Aumont (1995) argumenta que a função essencial do filme é mostrar os eventos representados e não deixar ver a si mesmo como filme.

A instituição cinematográfica tenta apagar do espetáculo fílmico os vestígios de seu trabalho, de sua própria presença. Tende-se a ter a impressão que a história está se contando, por conta própria, neutra e sem intermediários. Apresentando, em suma, uma história que se conta sozinha e que, com isso, adquire 
um valor essencial: ser como a realidade, imprevisível e surpreendente. Como se aquela imagem, produzida a partir de determinada perspectiva fosse completa e reunisse em si tudo que há para mostrar e saber. Para o espectador, inserido no interior do sistema representativo, é como se participasse deste mesmo espaço e, assim, já não percebesse os elementos da representação como tais, mas como sendo as próprias coisas, é como se a câmera mostrasse tudo que se tem a ver. Isto não significa concluir que ele seja a expressão transparente da realidade social, nem seu contrário exato.
As primeiras cenas de Simon apresentam essas características cinematográficas e também essa "vida de todos os dias, dos mesmos gestos...". Professor de natação, sua primeira cena é na escola, dando instruções a um aluno. É nesse ambiente que ele conhece Bilal, que deseja aprender a nadar. Na sequência, está no supermercado e encontra a ex-mulher, Marion. Em seguida, janta sozinho em um restaurante, volta para casa, pega as correspondências... enfim, uma vida comum, semelhante à de qualquer outra pessoa adulta, podemos dizer até um tanto sem graça.

Figura 1 - Simon em suas atividades cotidianas: aulas de natação, compras, zapping na TV.
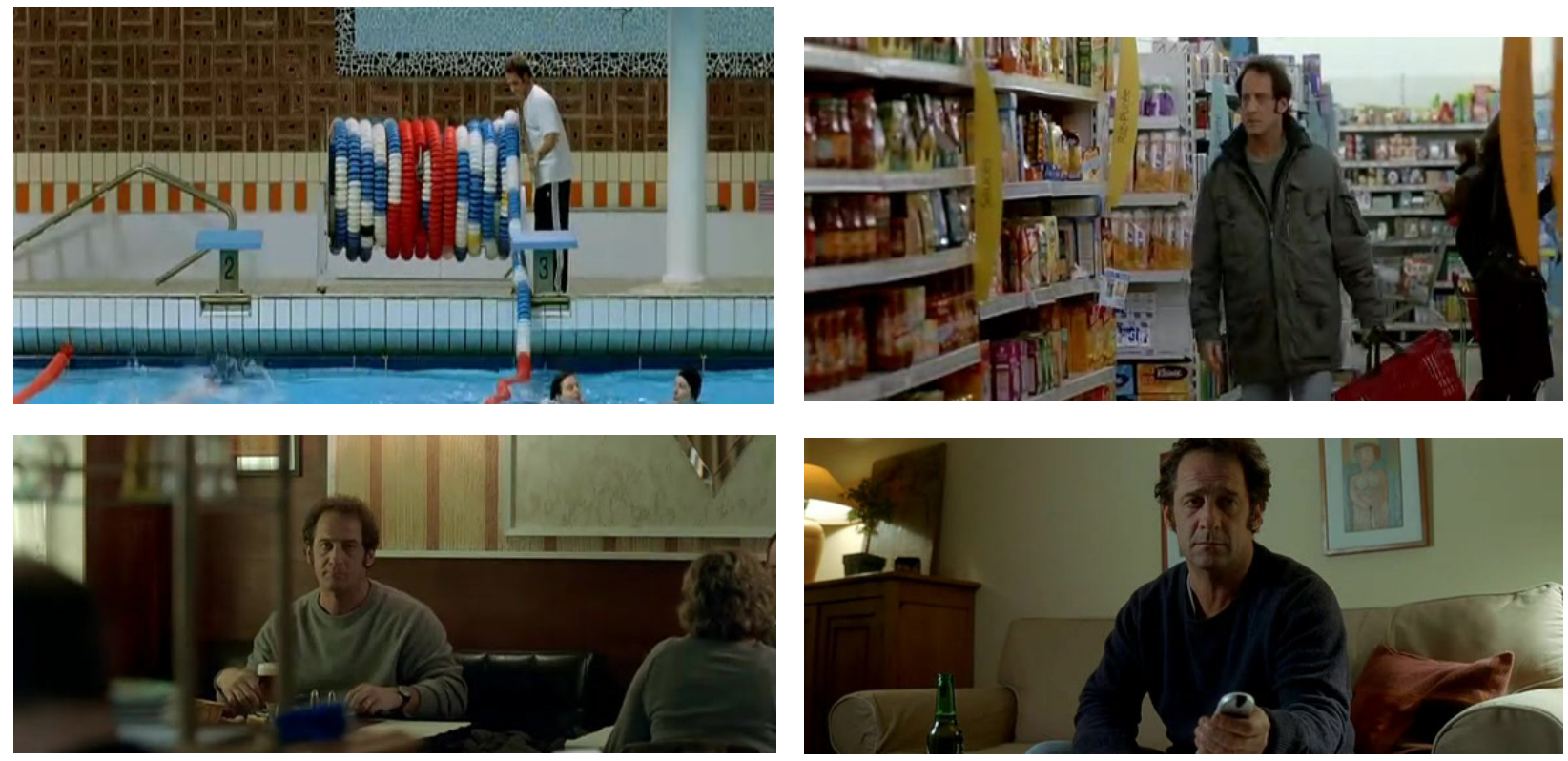

Esta rotina, porém, é alterada com a presença do jovem imigrante. Simon encontra em Bilal mais que um aluno, encontra o entusiasmo e a audácia tão característica dos jovens, a certeza de que o futuro será melhor, encontra o sonho. Este encontro, entretanto, não ocorre isento de tensionamentos. Ao perceber a falta de sua medalha de campeão olímpico, a primeira atitude de Simon é acusar Bilal. Da mesma forma, o vizinho esbraveja após a discussão "os imigrantes são sujos, têm doenças e roubam".

Para Bilal, o encontro com Simon, de certa forma, rompe a rotina de inseguranças, de incertezas, tão características da condição de imigrante. Bauman

(2007) afirma que ser imigrante é perder os meios em que se baseia a existência social, ou seja, um conjunto de coisas e pessoas comuns que têm significados - terra, casa, aldeia, cidade, país, posses, empregos e outros pontos de referência cotidianos. Além disso, encontrar-se diante de um dilema, cuja solução, se é que existe, é um tanto penosa. Expulso à força ou obrigado a fugir de seu país de origem, ele tem sua entrada recusada em qualquer outro lugar. Na verdade, não houve uma mudança consensual de lugar e sim uma perda. Ele é duplamente indesejado, pois não pode voltar para o lugar de partida, seja porque o país que deixou não o quer de volta ou 
porque o que dava significado e condições à sua vida já não existe mais - foi tomado, destruído; também não pode seguir adiante porque não é bemvindo em qualquer outro país. "Nenhum governo ficará satisfeito em assistir a um influxo de milhões de sem-teto. Todos fariam o possível para impedir que os recém-chegados se estabelecessem". Além disso, tem uma: localização 'permanentemente temporária', os refugiados 'estão lá, mas não são de lá'. Não pertencem realmente ao país em cujo território foram montadas suas cabanas ou fixadas suas tendas. Estão separados do resto do país que os hospeda por um véu de suspeita e ressentimento invisível, mas que ao mesmo tempo é espesso e impenetrável. Estão suspensos num vácuo espacial em que o tempo foi interrompido. Não estão estabelecidos nem em movimento; não são sedentários nem nômades (BAUMAN, 2007, p. 51).

Figura 2 - Incertezas e instabilidade da imigração: fiscalização policial, abrigo improvisado, alimentos doados
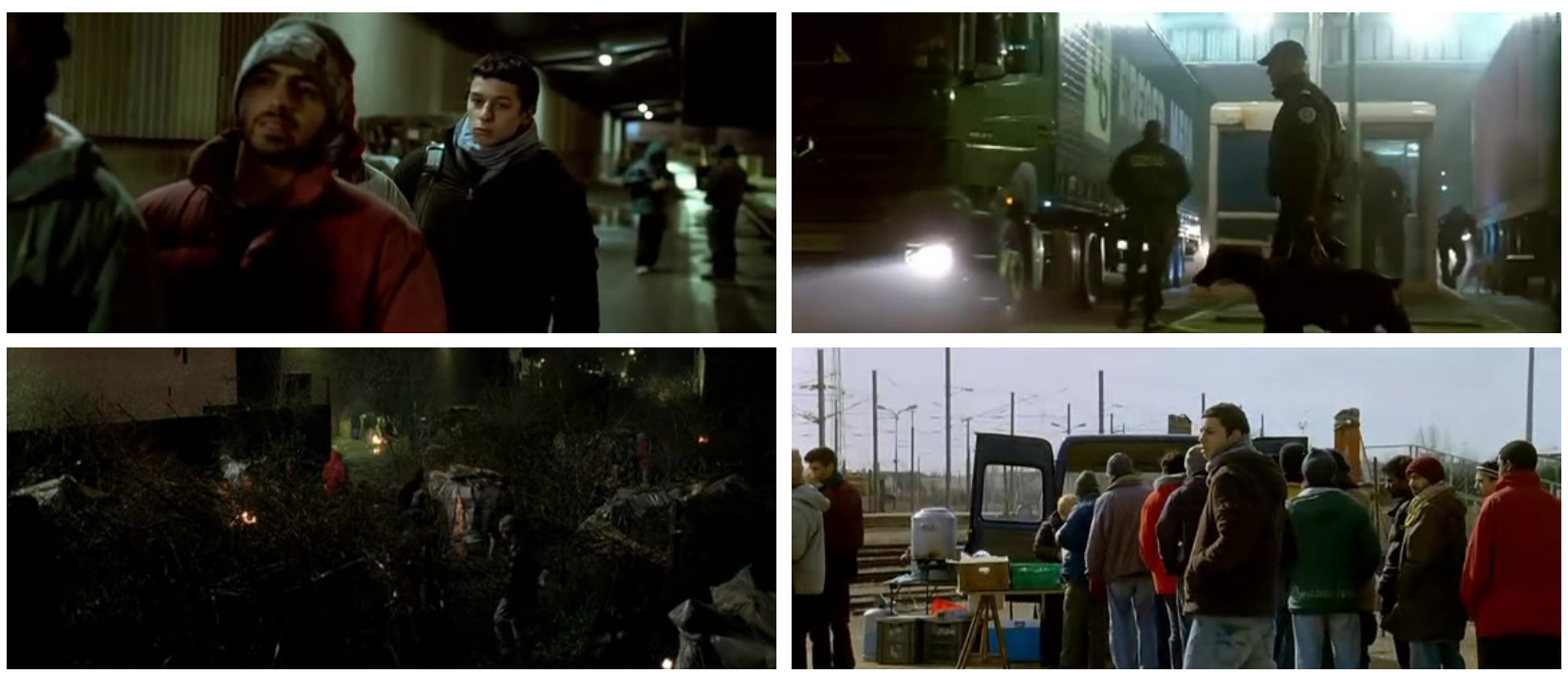

A imigração constitui-se, dessa forma, em espaço onde a recorrência a generalizações e estereótipos se faz constantemente necessária. Por sua vez, pode ser também meio para sua ruptura. Para Heller (2004), os juízos provisórios assim como os preconceitos são meros exemplos particulares de ultrageneralização. É característico da vida cotidiana, em geral, o manejo grosseiro do "singular". Sempre reagimos a situações singulares, respondemos a estímulos singulares e resolvemos problemas singulares. Para podermos reagir, temos de subsumir o singular, do modo mais rápido possível, sob alguma universalidade; é preciso organizá-lo em nossa atividade cotidiana, no conjunto de nossa atividade vital; em suma, temos de resolver o problema. Mas não temos tempo para examinar todos os aspectos do caso singular, nem mesmo os decisivos: temos de situá-lo o mais rapidamente possível sob o ponto de vista da tarefa colocada. É aquela situação de se atravessar uma rua, não são usados os princípios e os cálculos da física, mesmo porque a vida é dinâmica, não é possível fazer uma pausa para este tipo de cálculo, é preciso recorrer à experiência, a situações semelhantes e assim por diante. Neste caso, especificamente, a pausa impediria a ação.

A resposta no tempo necessário, então, só se torna possível graças à ajuda dos vários tipos de ultrageneralização. É assim, por exemplo, que se recorre à analogia. É através dela que, principalmente, funciona o nosso conhecimento cotidiano do homem, sem o qual, não poderíamos sequer nos orientar; classificamos, em algum tipo já conhecido por experiência, o homem que agora queremos, sob algum aspecto importante para nós e essa classificação por tipos permite nossa orientação. Tão-somente a posteriori, torna-se "evidente" na 
prática que podemos dissolver aquela analogia e conhecer o fenômeno singular [...]. Decerto, o juízo provisório de analogia pode se cristalizar em preconceito; pode ocorrer que já não prestemos atenção a nenhum fato posterior que contradiga abertamente nosso juízo provisório, tanto podemos nos manter submetidos à força de nossas próprias tipificações, de nossos preconceitos.

Para Bhabha (1998), o estereótipo é uma forma de conhecimento e identificação que vacila entre o que está sempre "no lugar", já conhecido, e algo que deve ser ansiosamente repetido. Isso possibilita oferecer, em um momento qualquer, um ponto seguro de identificação. Porém, por ser uma simplificação, uma forma presa, fixa constitui um problema para a representação do sujeito, pois nega o jogo da diferença que a negação pelo outro permite.

Desse modo, o juízo provisório analógico é inevitável no conhecimento cotidiano dos homens, mas está exposto ao perigo da cristalização; e, embora inicialmente o tratamento grosseiro do singular não seja prejudicial, pode converter-se num dano irreparável, se conservado após ter cumprido sua função. O juízo provisório, o pragmatismo, os precedentes, a mimese fazem parte do cotidiano, mas as formas necessárias da estrutura e do pensamento da vida cotidiana não devem se cristalizar em absolutos, têm de deixar ao indivíduo uma margem de movimento e possibilidades de explicitação.

Ainda de acordo com Heller (2004), chegamos à ultrageneralização característica de nosso pensamento e de nosso comportamento cotidianos de duas maneiras: a) por um lado, assumimos estereótipos, analogias e esquemas já elaborados; b) por outro, eles nos são "impingidos" pelo meio em que crescemos. Toda ultrageneralização é um juízo provisório, visto que se antecipa à atividade possível e nem sempre, muito pelo contrário, encontra confirmação no infinito processo da prática. Além disso, pode-se passar muito tempo, até percebermos, com atitude crítica, esses esquemas recebidos, quando se chega a produzir tal atitude.
No que se refere à imigração, corre-se o risco de não superar este primeiro momento, pois, de acordo com Rea e Tripier (2003), a imigração é apresentada sempre como um problema a resolver: como tratar a regularização dos "sans-papiers", a integração das gerações provenientes da imigração, o lugar do Islã nas sociedades europeias... Os discursos políticos e midiáticos fazem da imigração uma causa de insegurança. Carregada de incerteza, a própria palavra imigração veicula medo, pavor, causa estranhamento e distancia, ou seja, impede a convivência que permite dissolver a analogia e chegar ao singular.

Em Bem-vindo, as incertezas da imigração, do encontro com o outro, esta ultrageneralização característica do cotidiano são superadas na e pela convivência. É a convivência, em todos os seus aspectos, que possibilita a homogeneização que suspende o cotidiano e que permite retornar a ele modificado. É a convivência, o encontro com o outro, que possibilita ao homem desenvolver suas potencialidades e, antes disso, constituir-se realmente homem, para além da determinação biológica. Esta convivência se dá pela comunicação. É a partir da comunicação que o relacionamento com o outro é possível. E relacionar-se com o outro é essencial, pois, como afirma Flusser, quando encontro o outro, encontro-me face ao diferente de mim, ao estranho, ao estrangeiro, ao inimigo. "Encontro-me", isto é: identifico-me face ao outro. Torno-me sujeito (FLUSSER apud BAITELLO JUNIOR, 2010, p. 45).

\section{Considerações Finais}

Embora a presença do imigrante seja vista como necessária em aspectos econômicos, visto que, frequentemente, submete-se à remuneração inferior e condições de trabalho não aceitas pelos trabalhadores nacionais; sua presença social, como sujeito detentor e merecedor de direitos, não é reconhecida. Ao expor essas contradições da 
sociedade de acolhida, o imigrante é, ao mesmo tempo, fundamental e indesejado. Construir a imagem do imigrante vinculada à insegurança e problemas sociais, além de reforçar e fortalecer estereótipos, alimenta conflitos e atua no sentido de legitimar e justificar posturas políticas xenofóbicas que pregam o cerramento das fronteiras e a expulsão de estrangeiros, constituindo um encadeamento circular em que cada discurso serve como suporte e legitimação do outro.

Neste contexto, a temática da imigração tem adquirido centralidade em diferentes meios de comunicação de massa. Dentre eles, o cinema constitui-se um espaço privilegiado, por não funcionar sob a lógica opressiva do tempo e por oportunizar reflexões impossíveis em outros veículos. Um filme, como produto e veículo das representações que uma sociedade faz de si mesma, pode ser considerado representativo não apenas das condições técnicas de produção, mas, também ou principalmente, das condições sociais, dos tensionamentos e dos valores de sua época.

Desta forma, acreditamos que o cinema atue de maneira central na construção da imagem do imigrante e, também, na construção de identidades, visto que pode tanto promover o conhecimento, a identificação e o afeto ao outro, quanto divulgar estereótipos. Para Kehl (2003), na sociedade contemporânea, a dimensão simbólica do outro é toda recoberta pelo imaginário produzido pela indústria do espetáculo. $\mathrm{O}$ eu - nossa identidade face ao outro - é uma ficção, construída por identificações imaginárias e pelas narrativas que costuram o percurso dos sujeitos em "histórias de vida" plenas de intenções, causalidade e significação. Como afirma Baudrillard (2004), antes que a violência do real esteja lá e que a ela seja somado o arrepio da imagem, a imagem já está lá bem antes e a ela colase o arrepio do real.

Em um momento em que o estímulo e o apelo imagético são cada vez maiores, é preciso encontrar espaços em que o olhar, embora saturado, consiga novamente se encantar com as imagens e que elas possam realmente promover a intermediação do homem com o mundo. Bem-vindo faz isso de diferentes formas: o simples fato de se dirigir a uma sala de cinema ou mesmo assistir ao filme em casa rompe o processo cotidiano, permite um novo olhar. Com uma temática atual e oportuna, não são somente os personagens que suspendem o cotidiano e voltam a ele modificados.

\section{Referências}

AUMONT, Jaques et al. A estética dofilme. Tradução de Marina Appenzeller. Campinas: Papirus, 1995.

BAITELLO JUNIOR, Norval. A serpente, a maçã e o holograma: esboços para uma teoria da mídia. São Paulo: Paulus, 2010.

BAUDRILLARD, Jean; Morin, Edgar. A violência do mundo. Tradução de Leneide Duarte-Plon. Rio de Janeiro: Anima, 2004.

BAUMAN, Zigmunt. Tempos líquidos. Tradução de Carlos Alberto Medeiros. Rio de Janeiro: Jorge Zahar, 2007.

BHABHA, Homi K. O local da cultura. Tradução de Myriam Ávila, Eliana Lourenço de Lima Reis e Gláucia Renata Gonçalves. Belo Horizonte: Ed. UFMG, 1998.

HELlER, Agnes. $O$ cotidiano e a história. São Paulo: Paz e Terra, 2004.

KEHL, Maria Rita. Muito além do espetáculo. Disponível em: <http://www.mariaritakehl.psc.br/ resultado.php?id=77> Acesso em: 23 Ago 2011.

METZ, Christian. Ensaios sobre la significación en el cine. Buenos Aires: Tiempo Contemporáneo, 1972.

MORIN, Edgar. O cinema ou o homem imaginário. Tradução de António Pedro Vasconcelos. Lisboa: Moraes Editores, 1970.

NETTO, José Paulo; CARVALHO, Maria do Carmo Brant de. Cotidiano: conhecimento e crítica. São Paulo: Cortez, 2011.

REA, Andrea; TRIPIER, Maryse. Sociologie de 
l'immigration. Paris: Éditions la Découverte, 2003.

WELCOME. Diretor: Philippe Lioret. França: Imovision, 2009. DVD (155 min), color, língua original: francês. 
